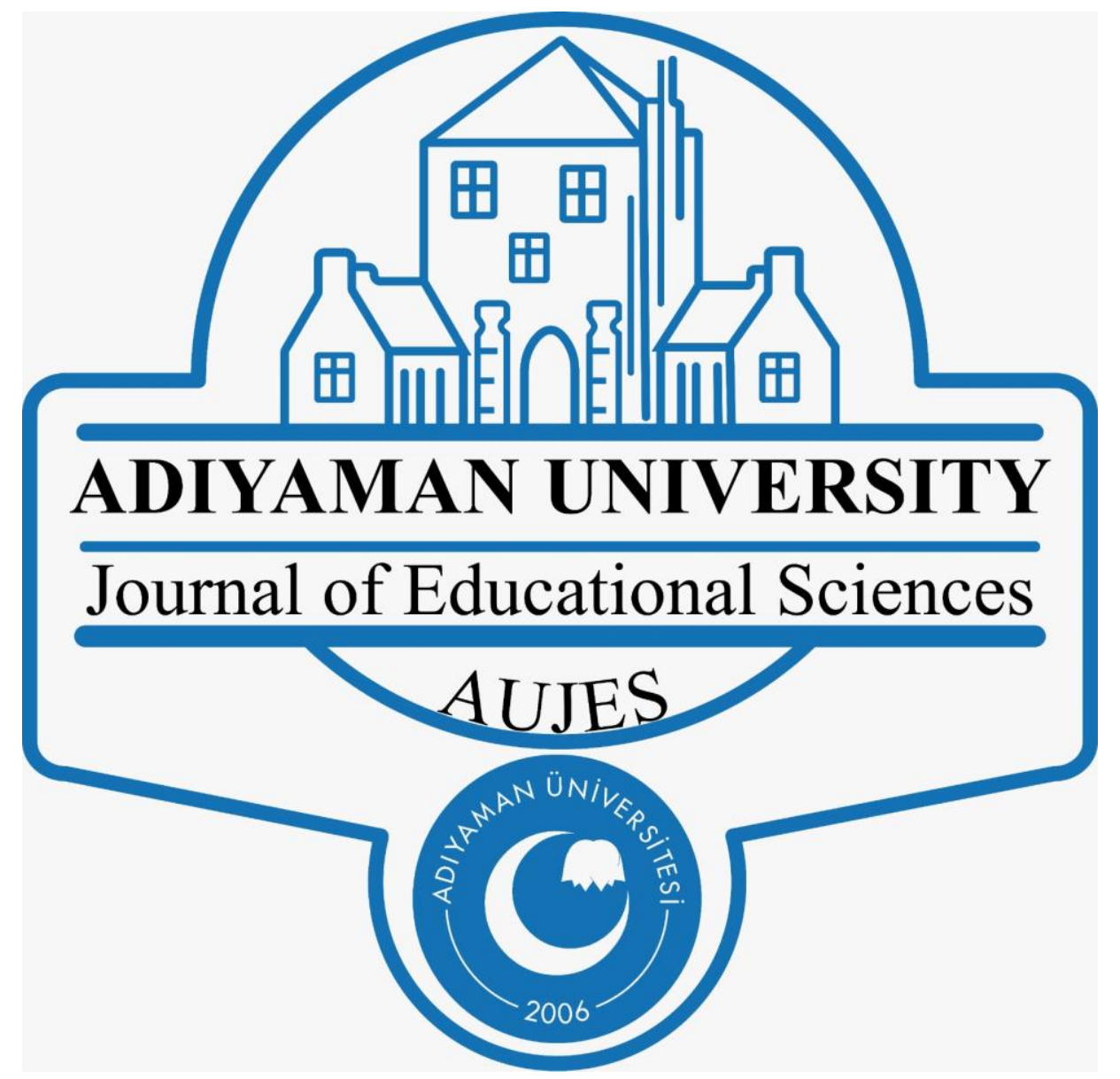

Article History

Received: 09.04.2019

Received in revised form: 04.08.2021

Accepted: 29.12.2021

Available online: 30.12 .2021

Article Type: Research Article

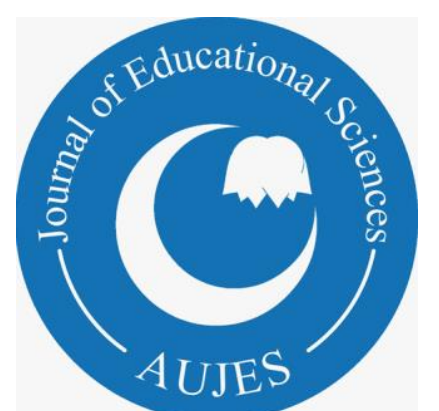

ADIYAMAN UNIVERSITY

Journal of Educational Sciences

(AUJES) https://dergipark.org.tr/tr/pub/adyuebd

Contextual Analysis of Proofs Without Words Skills of Pre-service Secondary Mathematics Teachers: Sum of Integers from 1 to $n$ Case

Kübra Polat ${ }^{1}$, Handan Demircioğlu ${ }^{2}$

${ }^{1}$ Sivas Cumhuriyet University, Department of Mathematics and Science Education, Sivas, Turkey (iD)

${ }^{2}$ Sivas Cumhuriyet University, Department of Mathematics and Science Education, Sivas, Turkey (iD

To cite this article:

Polat, K. \& Demircioğlu, H. (2021). Contextual analysis of proofs without words skills of pre-service secondary mathematics teachers: sum of integers from 1 to $\mathrm{n}$ case. Adiyaman Univesity Journal of Educational Sciences, 11(2), 93-106. 



\title{
Contextual Analysis of Proofs Without Words Skills of Pre-service Secondary Mathematics Teachers: Sum of Integers from 1 to $n$ Case
}

\author{
Kübra Polat ${ }^{\text {* }}$, Handan Demircioğlu ${ }^{2}$ \\ ${ }^{1}$ Sivas Cumhuriyet University, Faculty of Education, Sivas \\ ${ }^{2}$ Sivas Cumhuriyet University, Faculty of Education, Sivas
}

\begin{abstract}
Recently, studies have been carried out on alternative proof methods due to the change in the perspective of teaching proof and the difficulties of learners in proof. In this context, proof without words, which are presented as an alternative to proof teaching, defined by diagrams or visual representations and require the student to explain how proof is, are discussed in this study. The aim of this study is to examine pre-service mathematics teachers' explanations of proof without words about the sum of consecutive numbers from 1 to $\mathrm{n}$. The data were collected by the proof of the sum of consecutive integers. 27 pre-service teachers from a university in the Middle Anatolia region participated in this study, which was conducted using a basic qualitative research design. At the end of the study, it was seen that most of the preservice teachers were unable to explain the proof without words of the sum of integers from 1 to $\mathrm{n}$. One of the reason for this may be related to the spatial thinking skills of pre-service teachers. However, there are pre-service teachers who can interpret the visual given in the proof correctly, use the necessary mathematical knowledge, but cannot generalize using the given visual. The reasons why the pre-service teachers could not express the general situation are considered as the lack of algebraic thinking.
\end{abstract}

Key words: Proof, Proof teaching, Proofs without words, Visual proofs

\section{Introduction}

Proof plays an important role in the development of mathematical thinking skills. For this reason, it has been an important part of mathematics education at all grade levels. Finding a new proof is not possible at all levels. Heinze and Reiss (2004) state that formal proof can be done by experts, and this will not happen in school mathematics. On the other hand, according to Ugurel, Morali, Karahan and Boz (2016), everyone has the capacity to understand the proofs of theorems. For many students, however, the proof is a ritual without understanding (Ball, Hoyles, Jahnke, \& Movshovitz-Hadar, 2002). In this context, the perception towards proof has begun to change especially in recent years. This changing perception requires that proof convince the student and be practical (Almeida, 1996). In particular, new and alternative ways of learning and teaching for proof are investigated (Hanna, 2000; Polat, 2018). However, how students' deeper understanding of mathematical proof is seen as a difficult research area (Marrades \& Gutierrez, 2000).

Students who write in their notebooks without understanding the proofs made in mathematics lessons can gain the ability to follow the process instead of understanding. Producing arguments about proof provides understanding (Altun, 2014). Proof, which is seen as one of the basic elements of mathematics, is not only a goal of learning mathematics but also a tool that helps students to understand mathematical concepts (Kristiyajati \& Wiyaja, 2018). In this context, proofs without words (PWW) are presented as an alternative way to proof teaching because they are diagrams or pictures that help us to see why a mathematical expression is correct (Gierdien, 2007; Alsina \& Nelsen, 2010).

When the purpose of the proof is to clarify the mathematical expressions and to convince the student of the correctness of the mathematical expression, pictures and diagrams offer mathematical expressions from a different perspective (Thornton, 2001). Using the objects instead of numbers and properly aligned with the resulting models, the relationship between operations and numbers can be revealed. At this point, Rinvold and Lorange (2011) argue that discussing with objects representing numbers is important for proof teaching. Because in the theorems about natural numbers, insight can be gained when numbers are used as objects (Alsina

\footnotetext{
* Corresponding Author: Kübra Polat, kubraapolaat@hotmail.com.tr
} 
\& Nelsen, 2010). Additionally, using numbers as objects is the essence of algebraic thinking. Showing numerical relationships using geometric representations leads to a relational approach rather than a numerical one. This is a way to improve algebraic thinking (Flores, 2000; Thornton, 2001). On the other hand, teachers who privilege only algebraic representations prevent their students from establishing relationships in the process of proving (Duval, 1999). As a matter of fact, Dogan (2019) revealed that although teachers believe that symbolic representations are abstract, they believe that proofs should always include symbolic representations.

\section{Theoretical Framework}

Proofs show that the information given in the theorem is consistent with the axioms and mathematical results. Therefore, while there is sentence reasoning in classical proofs, there are "visual information", "visual argument" and "visual reasoning" in proofs without words using visuals. When Proofs without words are well organized, they are easily represented by points or concrete objects, and the resulting patterns can be easily seen (Miller, 2012). Cain (2019) has handled proof without words as proofs using spatial thinking. For this reason, he called proofs without word as spatial proofs. According to him spatial proofs are simpler than the inductive proofs. In many sources, proofs without words about integer sums are included (Cain, 2019; Nelsen, 1993; 2000; Lam, 2007; Larson, 1985; Giaquinto, 2007). As a matter of fact, there are many different ways of proving the formula of the sum of consecutive integers from 1 to $n$, or showing the accuracy of the formula. Indeed, Lam (2007) uses spatial visualization, Gauss method, pairing of terms, statistical approach, using counting arguments, using binomial coefficients, using relations involving binomial expansions, using the coefficients of binomial expansions, method of difference, mathematical induction, and many other methods to show the way to prove the formula of the sum of integers. In Lam's study, Lam (2007) referred to books written by Nelsen $(1993 ; 2000)$ without mentioning proofs without words under the title of "spatial visualization". Larson (1985) showed different proofs under the headings of draw a figure, finite differences, mathematical induction, search for a pattern, counting argument, one-to-one correspondence, recurrence relations, generating function, Calculus, constructive combinations. Under the heading "Draw a figure" he has included many different examples of proofs without words. In Lam's (2007) and Larson's (1985) studies, only the sum of consecutive numbers from 1 to $\mathrm{n}$ is taken as a basis. On the other hand, Giaquinto (2007) stated that there are four ways to show the accuracy of the sum of the numbers from 1 to $n$. These are inductive, Gaussian, pebble or dot, square arguments. The proofs defined as pebble (dots) and square arguments are given under the name of visual proof. Also, Nelsen $(1993 ; 2000)$ has included many different visual proofs in his books regarding the sum of the numbers from 1 to $\mathrm{n}$.

Proofs without words are used in many proofs such as geometric theorems, number theory, trigonometry, general mathematical inequalities (Alsina \& Nelsen, 2010; Bell, 2011). Nelsen (1993; 2000) categorized in his book as geometry and algebra; trigonometry, calculus and analytic geometry; inequalities; integer sums, setsseries and mixed proofs without words. Davis (1993) states that proofs without words can be used to show all results of plane and solid geometry, high mathematics theorems with visual basis and graphical representations of applied mathematical results. Hanna (1990) used the concepts of "explanatory proof" and "a proof that proves". In the case of the sum of the first n numbers, Hanna stated that the "a proof that proves" is a mathematical induction, while she expressed the "Gaussian rule" and the visual consisting of the points in the right isosceles triangle in Figure $2 \mathrm{~b}$ as "the explanatory proof". According to this visual, the dots form isosceles right triangles containing $S(n)=1+2+3+\ldots+n$ dots. Jamnik, Bundy and Green (1997) presented a taxonomy, including "non-schematic proofs", "schematic proofs" and "inductive proofs" for proofs without words.

a)

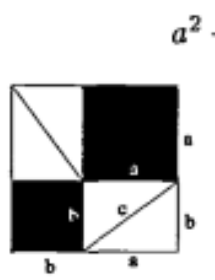

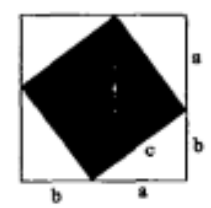

b)

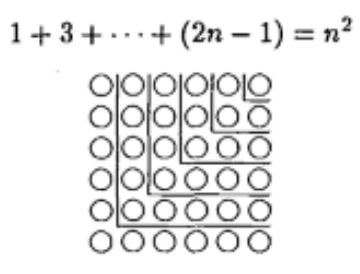

c)

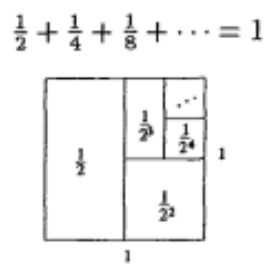

Figure 1. Schematic-non-schematic-inductive proof

According to this taxonomy, non-schematic proofs are evidence that show the accuracy of the situation with simple geometric manipulations on the diagram without induction as shown in Figure 1a. So, we can say nonschematic proofs prove the general situation. Schematic proofs are evidence that require induction for the state 
of the n. dimension, which does not require inductive steps to prove the theorem in each of the special cases, as shown in Figure 1b. As shown in Figure 1c, inductive proofs are evidence that require the inductive step to prove each concrete situation of the diagram. The example given in Figure $1 \mathrm{~b}$ is similar to the generic examples from Balacheff's (1988) proof schemes (Figure 2). General examples show a certain number and form the basis for a more general argument and are in an important position in terms of providing explanation and opinion (Dogan, 2020).

Balacheff (1988) stated that direct demonstration is the most basic form of proof and that it constitutes a transition stage from pragmatic proofs to conceptual proofs. As a matter of fact, as can be seen in Balacheff's example, it visualizes the $1+3+5+7$ process. Based on this example, it is expected that the general form of the formula $1+3+\cdots+(2 n-1)=n^{2}$ will be reached. But for Giaquinto visual methods cannot model infinite processes adequately (Dove, 2002). For this reason, according to some, diagrams are elements that can be used as an explanation of proof rather than proof (Doyle et.al., 2014; Rodd, 2000). Bardelle (2010) stated that visual arguments are far from being accepted as legitimate arguments for rigorous proofs, probably because they can easily misinterpret and therefore lead to false inferences. On the other hand, for some researchers, diagrams can be a proof like formal proofs. (Alsina \& Nelsen, 2010; Brown, 1997; Hanna, 1990).

a)

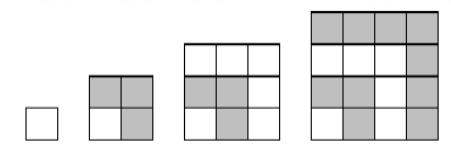

b)
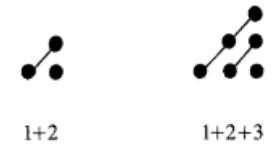

$1+2+3$

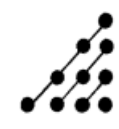

$1+2+3+4$

Figure 2. Sum of integers (Balacheff, 1988; p. 216)

According to some researchers since diagrams are individual examples of mathematical concepts students could not draw general conclusions from reasoning based on these (Dove, 2002; Kulpa, 2009). Despite the generalization problem, proofs without words are important tools in terms of being explanatory. These proofs have a powerful potential to serve as a bridge between empirical proofs and deductive proofs (Dogan \& William-Pierce, 2021). In the study of Dogan and William-Pierce (2021) they stated that teachers struggle to distinguish generic examples from visual representations and think visual representations and generic examples to be the same. So, they said that teachers have important misconceptions about generic examples type proofs. Kulpa (2009) proposes a hybrid model to avoid this generalization problem. In this model there are textual labels associated with diagram. According to Kulpa (2009) by adding an explanation or representation about which number the dots represent, it is clarified the reasoning even further and provide the correspondence between the diagrammatic proof and formulation of the theorem. For example in Figure $3 \mathrm{a}$ it is a diagram for $S(5)=1+2+3+4+5$. But in Figure $3 \mathrm{~b}$ it is a diagram for $S(n)$.

a)

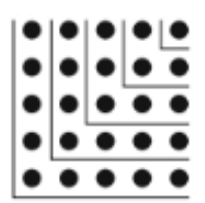

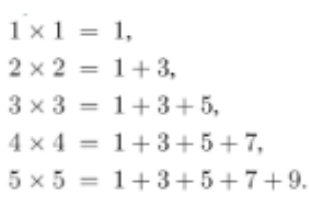

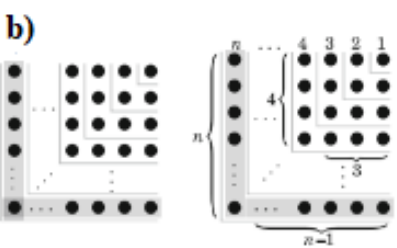

$1+3+5+7+\ldots+(2 n-1)=n^{2}$

Figure 3. Hybrid representation (Kulpa, 2009; p. 90)

PWW have a powerful potential to bridge between empirical proofs and complete deductive proofs, so context of these proofs is an important research area (Dogan \& William-Pierce, 2021). The proof without words, which is related to the sum of consecutive integers, especially based on many studies, has been used in this study. The purpose of this study is to examine the explanation of pre-service secondary mathematics teachers the proof without words which is related to the sum of consecutive numbers from 1 to $\mathrm{n}$. In this context, the research questions of this study are: 
1. Can do the preservice secondary mathematics teachers explain the proof without words of sum of 1 to $\mathrm{n}$ ?

2. How do the preservice secondary mathematics teachers explain the proof without words of sum of 1 to $n$ ?

\section{Method}

Basic qualitative research is the most common form of qualitative research that can be seen in all discipline and practice areas. In these studies, which questions are asked, what is observed, which documents are considered relevant depend on the theoretical framework of the study. (Merriam, 2013, p.22). In basic qualitative research classified by Merriam (2013), data can be collected by observation, interview and document analysis, as in another qualitative research. In the data analysis of this research type, the repetitive patterns that characterize the data are tried to be determined. Findings are themes supported by these recurring patterns. The whole interpretation is that the researcher understands the phenomenon he is interested in. In this study, pre-service teachers were asked to explain the PWW, and these explanations were analyzed. Written explanations and drawings they made regarding the PWW given to the pre-service teachers were accepted as documents. The main purpose of this study is to reveal and interpret how pre-service mathematics teachers explain the PWW. For this reason, this study, which aims to understand and interpret the explanations of pre-service mathematics teachers about the PWW of the sum of the consecutive numbers, is considered as a basic qualitative research. Researchers of this study, in their previous studies, obtained results about the difficulty in proof without words at all levels. They observed that students cannot generalize from a single example situation given in the visual (Demircioglu and Polat, 2015; Demircioglu and Polat, 2016; Polat and Akgün, 2020). In order to examine this problem, the data collection tool selected, and the explanations of the preservice mathematics teachers about the proof without words analyzed. 27 preservice mathematics teachers in the senior class of mathematics education department from a university in the Middle Anatolia region attended the study. Data were collected in the spring semester of 2017-2018. Considering that the preservice mathematics teachers are in the final year, they are considered to have sufficient conceptual and operational knowledge levels in mathematics, and they are also successful in taking the mathematics education courses in the program.

\section{Data Collection and Analysis}

A few steps were followed while choosing the proof without words to be included in the data collection tool. Firstly, we saw that in many studies (Lam, 2007; Larson, 1985; Giaquinto, 2007) the sum of the consecutive numbers was chosen as the context and different proof methods were studied with the sum of the consecutive numbers. Although there are many different proofs, prototype images are used. Therefore, in this study, the sum of consecutive numbers is taken as a basis. After this, we examined the proofs without words related with the sum of the consecutive numbers. We saw that there are many visuals with similar thinking processes but with some differences. After the examinations, the visuals were grouped under two groups.

In the first group of proofs without words about the sum of consecutive numbers are shown in Figure 2a and Figure $2 \mathrm{~b}$ by Nelsen (1993) and in Figure 2c by Britz, Mammoliti and Sørensen (2014).

a)

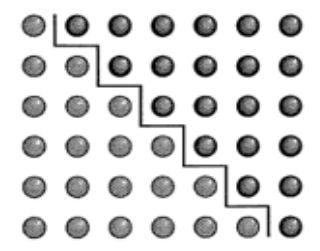

b)

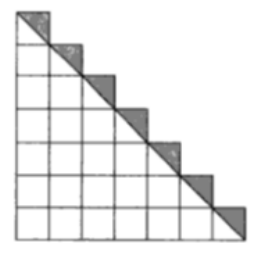

c)

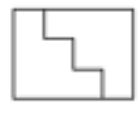

Figure 4. Single case visuals related to the sum of consecutive numbers

When the visuals given in Figure 4 are examined, it is seen that in Figure 4a the dots are used, in Figure $4 \mathrm{~b}$ squares are used and in Figure 4c neither the dots nor the squares are used. Furthermore, in the second group of PWW given by Nelsen (2000) regarding the sum of the numbers 1 to $n$ is as in Figure 5a. In Figure 5b, Alsina and Nelsen (2010) gave a similar visual to this PWW. 
a)

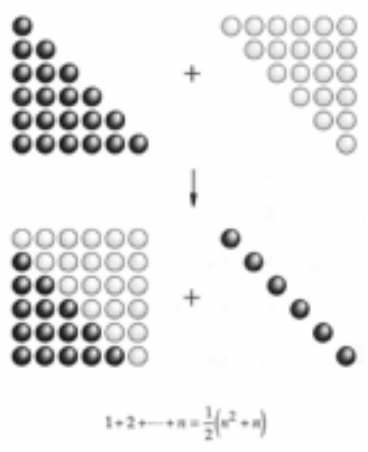

b)
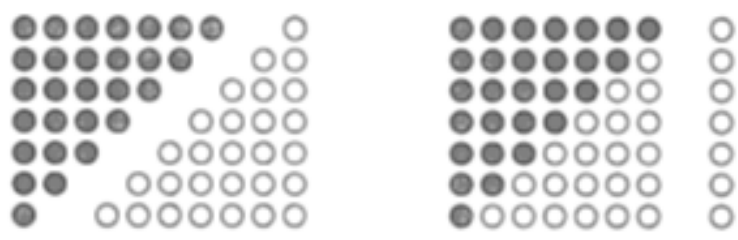

Figure 5. Visuals with two cases related to the sum of consecutive numbers

As seen from the Figure 4 and Figure 5, in the first group there is no visualization of the process of the dots or the squares arranging; but in the second group there is visualization of the process of arranging dots. When the visual in Figure 5a is examined, there is an emphasis on combining the figures with "+", but there is no emphasis in Figure 5b. Therefore, the visual shown in Figure 5a is thought to be more directional than the image in Figure 5b. On the other hand, while the visuals given in Figure 4 are given in one case, the visuals given in Figure 5 emphasize that the process displacement of the dots and a new form of reasoning should be judged in this way. In view of this situation, the visuals given in Figure 5 are taken as a basis. As a result, since it emphasizes both the situation and the combination, in this study the visual in Figure 5a for the sum of integers from 1 to $n$ by S. J. Farlow in the book "Proof Without Words II" by Nelsen (2000, p. 83) was selected as a data collection tool. The proof without words of the sum of consecutive numbers was given to preservice mathematics teachers and they were asked to explain the proof without words. Preservice mathematics teachers were given sufficient time to explain the proof without words. Then their written explanations were collected.

Firstly, the data collected in writing was transferred to the computer environment. The answers of the preservice mathematics teachers were examined by two experts and important expressions were defined and the main themes were determined with content analysis. No answer, unaccepted and accepted categories are created. There are sub-categories under "No answer" category, "blank, writing number of dots and expressing the number of dots with n"; under "Unaccepted" category "over generalization, those who did not use the second case for explaining the visual for $\mathrm{n}$, showing the accuracy for $n=6$ and Gauss method"; and under the "Accepted" category "accurate generalization, accurate generalization (emphasis on diagonal), explaining visual for n". After the main themes were determined, the findings were revealed by examining the relationship between each case and other situation.

\section{Results}

The explanations of the preservice teachers about the proof without words of the sum of consecutive numbers were analyzed. The explanations obtained from the question in the data collection tool are summarized in Table 1.

Table 1. Answers to the solution of proof without words regarding the sum of consecutive integers

\begin{tabular}{|c|c|c|c|c|}
\hline Categories & Subcategories & $f$ & Total & $\%$ \\
\hline \multirow[t]{3}{*}{ No answer } & Blank & 5 & & 18 \\
\hline & Writing number of dots & 4 & 12 & 14 \\
\hline & Expressing the number of dots with $n$ & 3 & & 11 \\
\hline \multirow[t]{4}{*}{ Unaccepted } & Over generalization & 1 & & 4 \\
\hline & $\begin{array}{l}\text { Those who did not use the second case for explaining the } \\
\text { visual for } n\end{array}$ & 2 & 7 & 7 \\
\hline & Showing the accuracy for $n=6$ & 1 & & 4 \\
\hline & Gauss method & 3 & & 11 \\
\hline \multirow[t]{3}{*}{ Accepted } & Accurate generalization & 2 & & 7 \\
\hline & Accurate generalization (Emphasis on diagonal) & 5 & 8 & 18 \\
\hline & Explaining visual for $\mathrm{n}$ & 1 & & 4 \\
\hline
\end{tabular}


As can be seen from Table 1, the answers of 12 preservice mathematics teachers were placed under the "no answer" category. 5 preservice teachers in this category have been coded as "blank" since they did nothing. 4 preservice mathematics teachers tried to count the dots in the row in the given image (Figure 6a, Figure 6d), in the column (Figure 6b) or in the diagonal (Figure 6c). Therefore, the given answers are coded as "Writing the number of dots". However, the preservice mathematics teachers did not provide any explanation for providing relationship. For this reason, these answers are placed under the category of "no answer". The answers of the preservice mathematics teachers are given in Figure 6.

a)

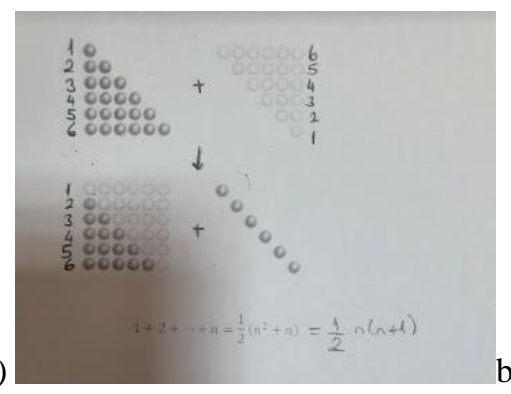

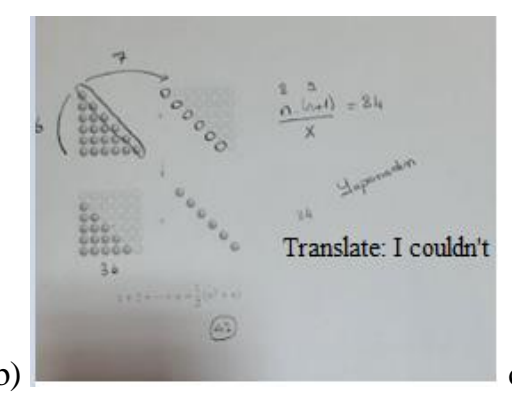

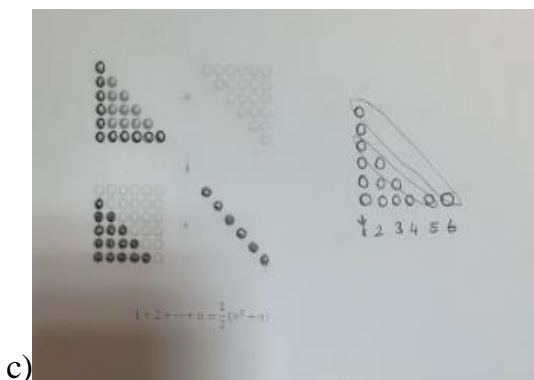

d)

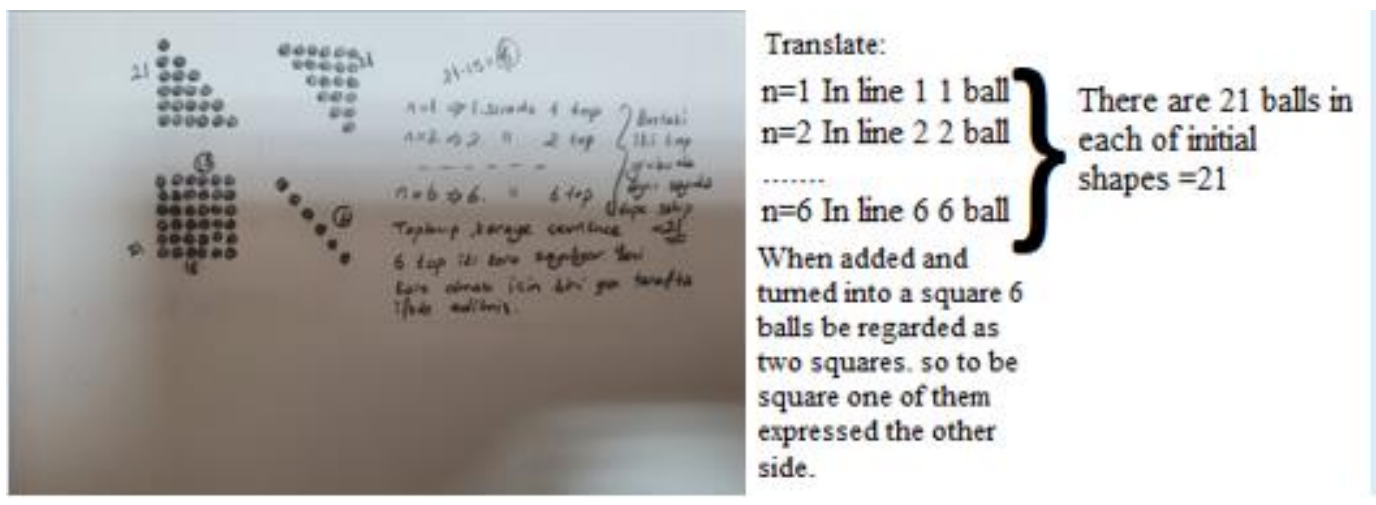

Figure 6. Answers to the category "No answer"

The other 3 preservice mathematics teachers in this category counted the dots in the same way as the preservice mathematics teachers who tried to find the number of dots, but as a difference they tried to associate certain number of dots with $\mathrm{n}$ (Figure 7). Therefore, these answers are also expressed in the subcategory of "Expressing the number of dots with n". One of the preservice mathematics teachers counted the dots in the column in the first case in the visual as seen in Figure 7a, and generalized the number of dots to n. The preservice mathematics teacher, then thought that the second case was a $n x n$ square. Unlike the previous preservice teachers (Figure $7 \mathrm{~b}$ ), the other preservice mathematics teacher generalized the number of dots without counting the number of dots. The third preservice mathematics teacher, as opposed to the previous preservice mathematics teacher, wrote the number of dots in the second case as $n^{2}$ and $n$ as seen in Figure 7c, and from here it was interpreted the first case as $\frac{n^{2}+n}{2}$.

a)

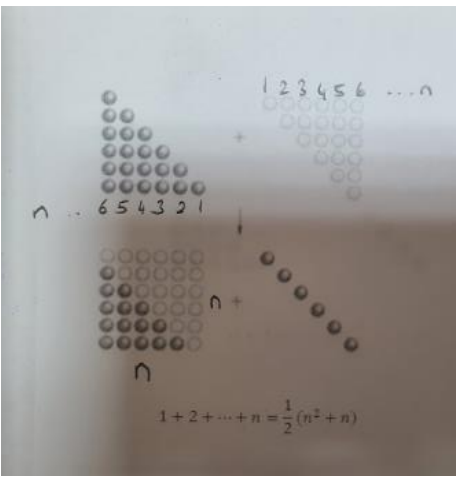

b)

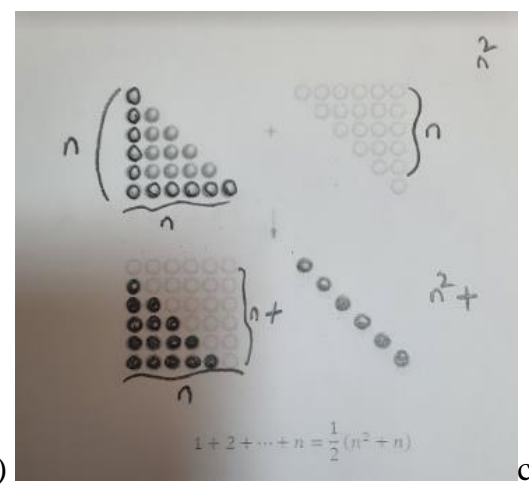

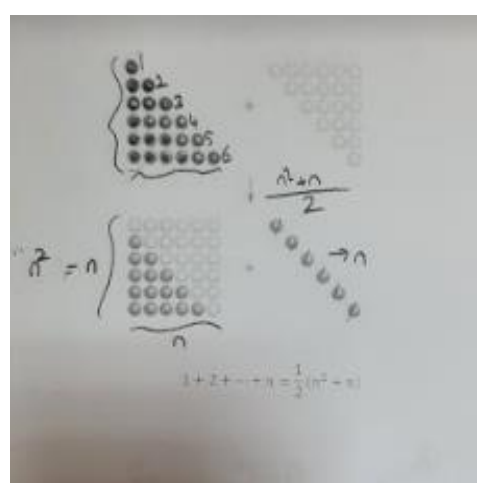

Figure 7. Answers for subcategory of "Expressing the number of dots with n" 
When Table 1 is examined, it is seen that there are 7 answers in the "Unaccepted" category. These were categorized under the following sub-categories: 2 preservice mathematics teachers "those who did not use the second case for explaining the visual for n"; 3 preservice mathematics teachers "Gauss method"; 1 preservice mathematics teacher "Over generalization" and 1 preservice mathematics teacher "Showing the accuracy for $n=6$ ". When the answers were examined, two preservice mathematics teachers (Figure 8a, $8 \mathrm{~b}$ ) were able to reach the formula considering the first case in the given image. Thus, for the sum of the numbers from 1 to $n$, they formed a rectangle with side lengths $n$ and $(n+1)$, by combining the two isosceles triangles. They expressed that the asked formula was half of the area of the rectangle and that is, $\frac{n \cdot(n+1)}{2}$. This is a correct approach, but it is not an explanation of this image because it does not take into account the second case given in the visual. In Figure 8c, the preservice mathematics teacher wrote that it could be $n$. $n+n$ for $n$. case $n . n+n$ dot after drawing the $n=1, n=2$ and $n=3$ cases of the given visual. Namely instead of reaching the formula using the $n$. case relationship, the preservice mathematics teacher tried to reach the formula by taking into consideration all the cases from 1 to $\mathrm{n}$. So, although it was sufficient to write $n . n+n$, the preservice mathematics teacher wrote $\left(1^{2}+2^{2}+\cdots+n^{2}\right)+(1+2+\cdots+n)$ because he/she took into account all the cases.

a)

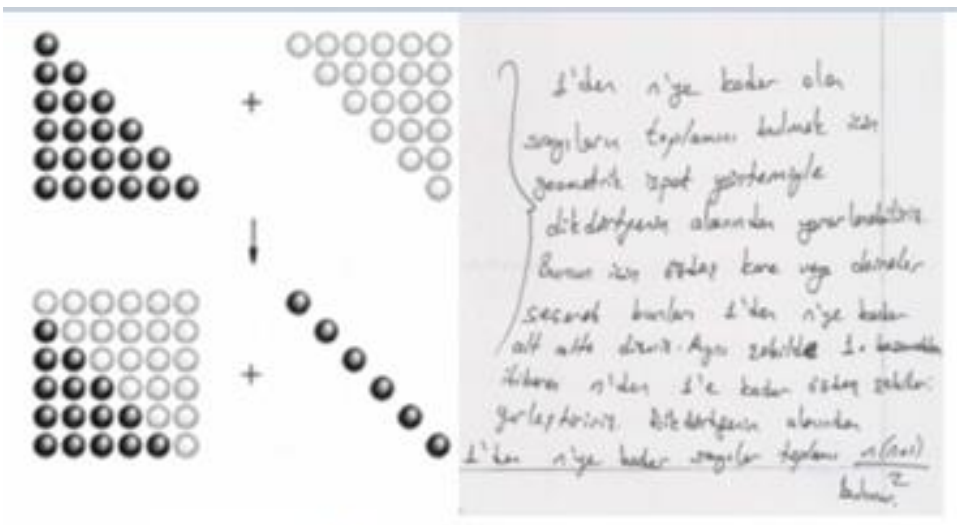
Translate: We can use the area of the rectangle by the geometric proof method to find the sum of numbers 1 to $\mathrm{n}$. for this we select squares or circles and arrange them 1 to $n$ under one another. likewise, we arrange it form $n$ to 1 . then we find it from the area of rectangle.

$$
1+2+\cdots+n=\frac{1}{2}\left(n^{2}+n\right)
$$

b)

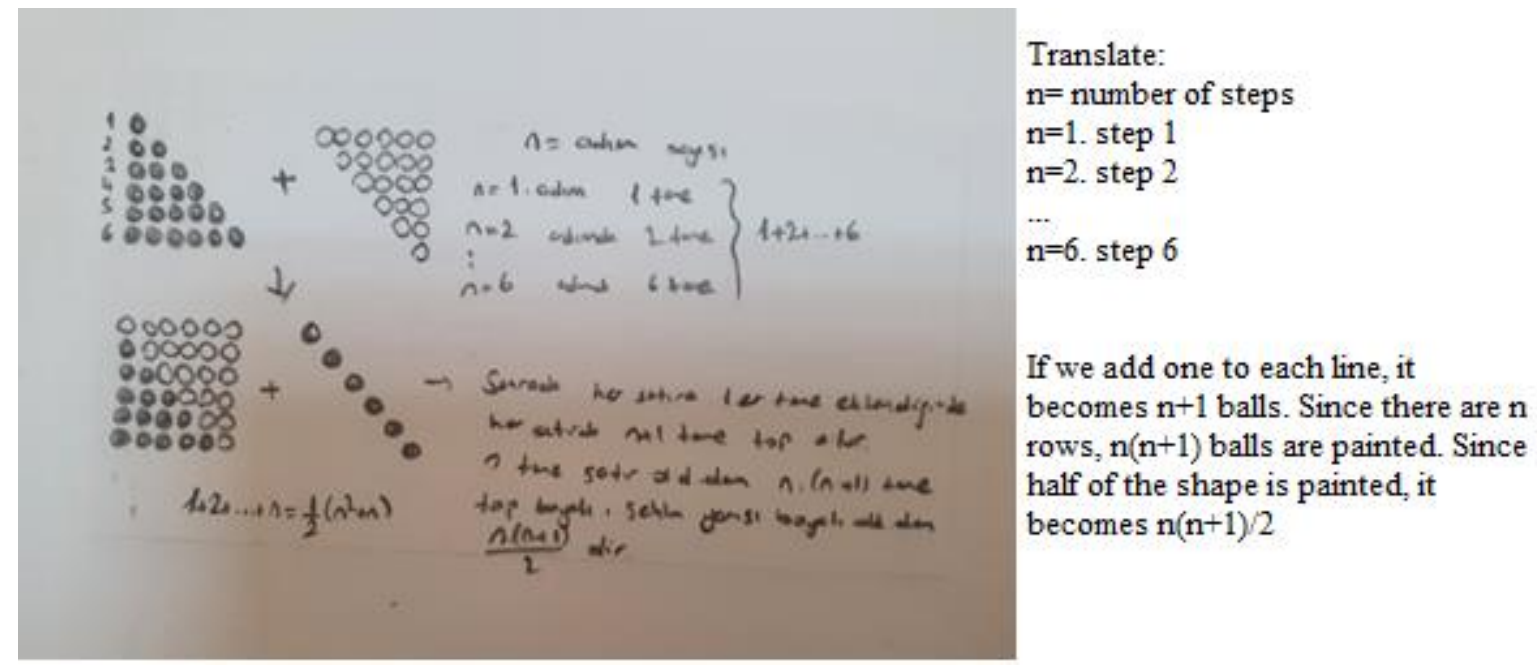


c)

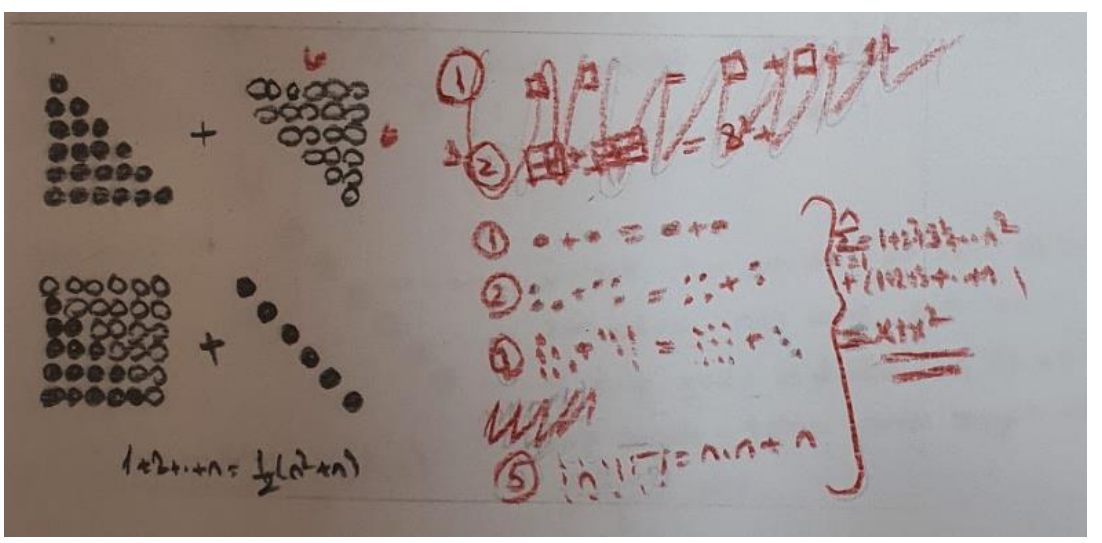

Figure 8. Answers for "Unaccepted" category

3 preservice mathematics teachers, regardless of the dots and relationships in the visual, proved the given formula by the method attributed to Gauss, whom they knew previously (Figure 9). But this is not the asked answer.
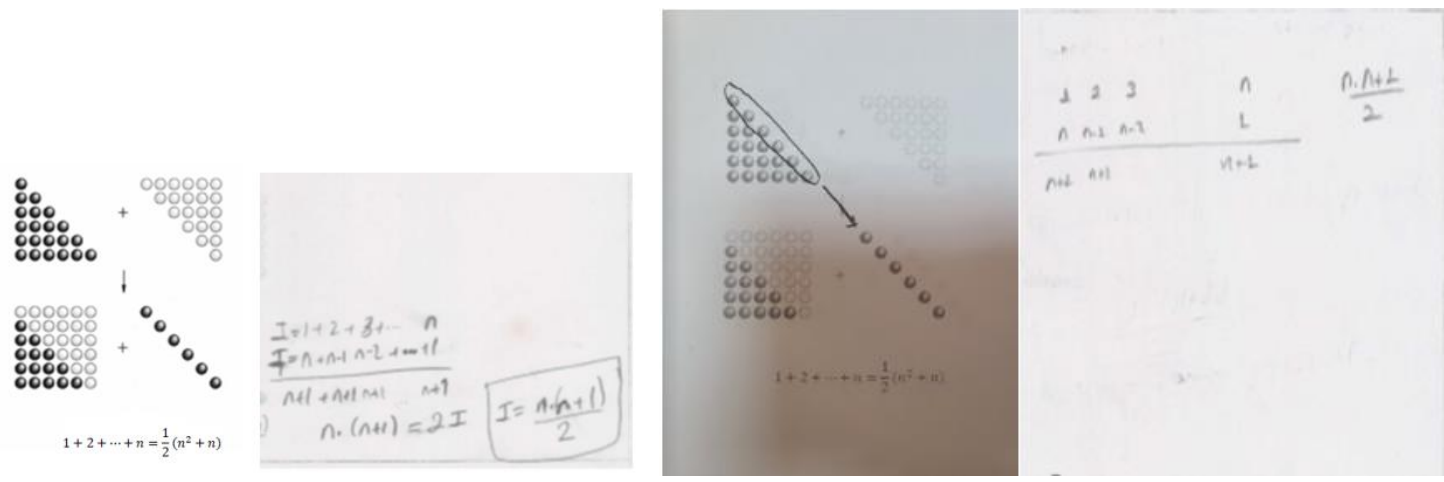

Figure 9. The answers of the subcategory of "Proof by Gauss method"

A preservice mathematics teacher showed the accuracy of the equation from the area of the triangle and square for $n=6$ as given in Figure 10 .

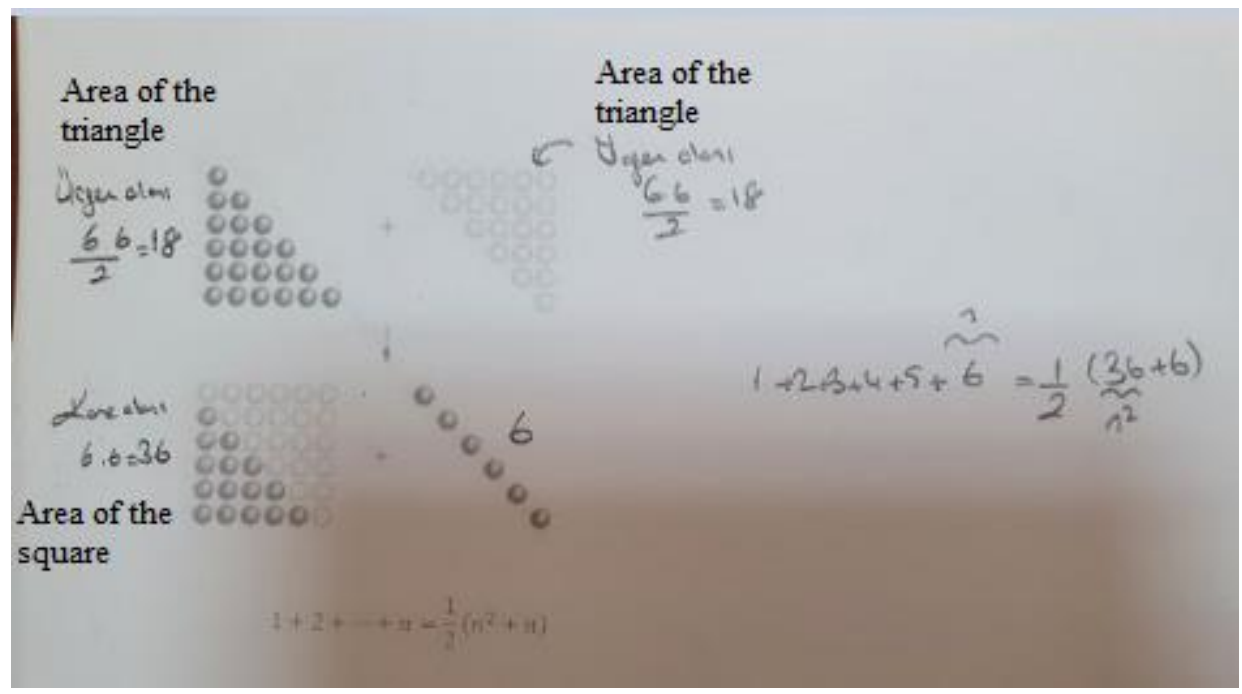

Figure 10. Answers for the sub-category of "Showing accuracy for $\mathrm{n}=6$ "

When Table 1 is examined, it is seen that 8 preservice mathematics teachers' answers are in the "Accepted" category. 7 of these answers are coded under the "accurate generalization" subcategory. In 5 of the answers in the "accurate generalization" subcategory, the emphasis was made on diagonal, in 2 of the answers 
no emphasis was made on diagonal. Therefore, the answers were interpreted separately. The remaining preservice mathematics teacher was evaluated under the subcategory of "using the visual for n". As a matter of fact, a preservice mathematics teacher whose answer was given in Figure 11a, initially interpreted the visual for $n=6$. As can be seen from Figure 11a, in the first case, considering the sum of the two isosceles triangles, $6.7=42$ was written and the relationship between the second and the first case was established. Then, he/she expressed this relationship as "if $n$ dots are added to the square, whose area is $n^{2}$, it is equal to twice the sum of the parts in the first case". Then he/she wrote the equation $n^{2}+n=2(1+2+\cdots+n)$ and he/she showed the right side of the equation with the first case of the visual and the left side with the second case with the arrows. Similarly, another preservice mathematics teacher explained the visual for the given $n=6$ case as shown in Figure $11 \mathrm{~b}$ and reached the formula for $n$.

a)

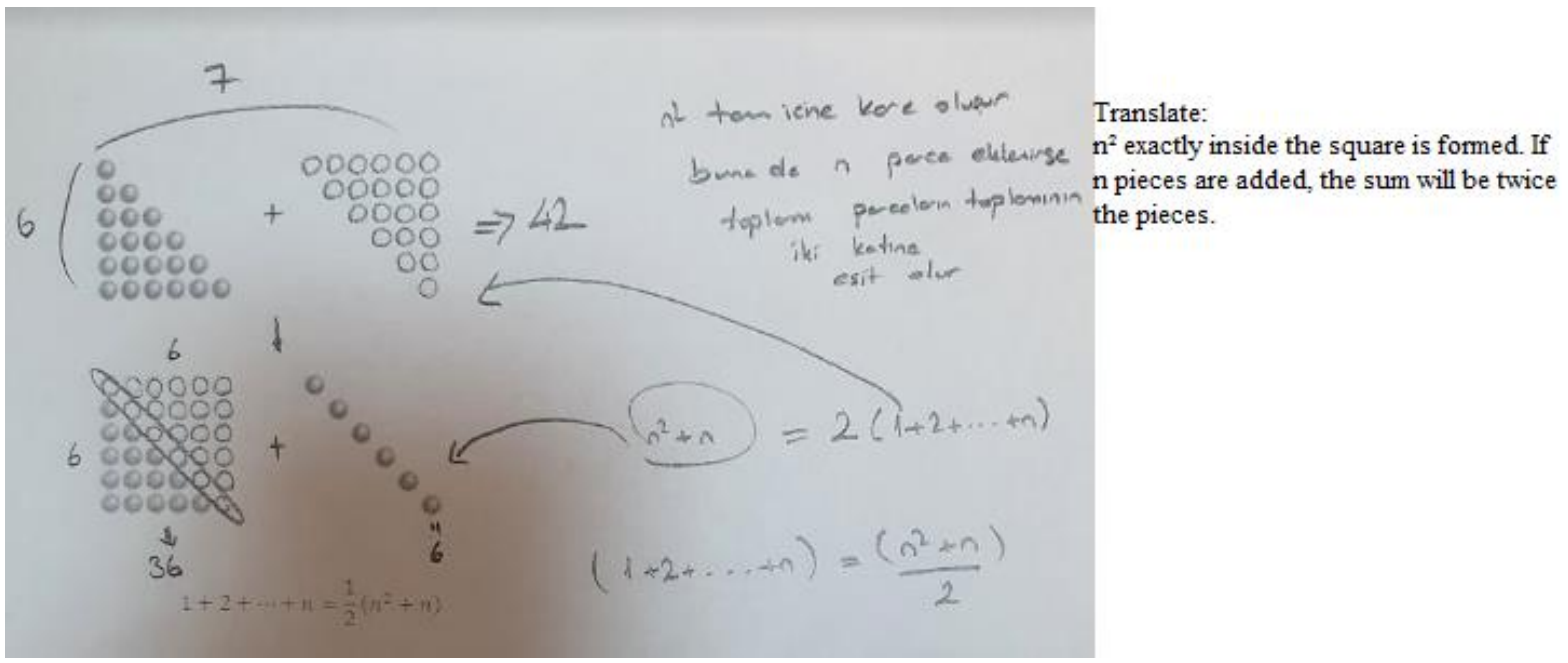

b)

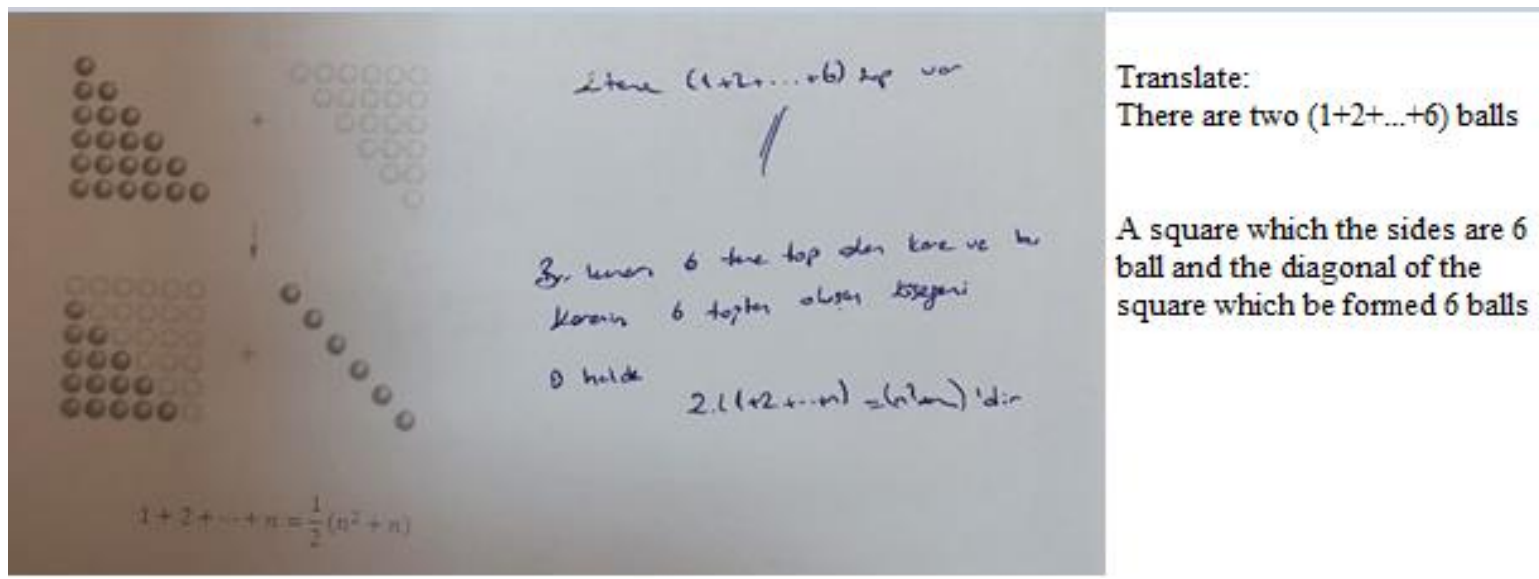

Figure 11. Answers of the "Accurate generalization" subcategory

As shown in Figure 12, 5 preservice teachers explained the visual given without mentioning the special case. All 3 preservice mathematics teachers pointed out that a square and a diagonal formed when the isosceles triangles were combined and thus expressed the formula. 


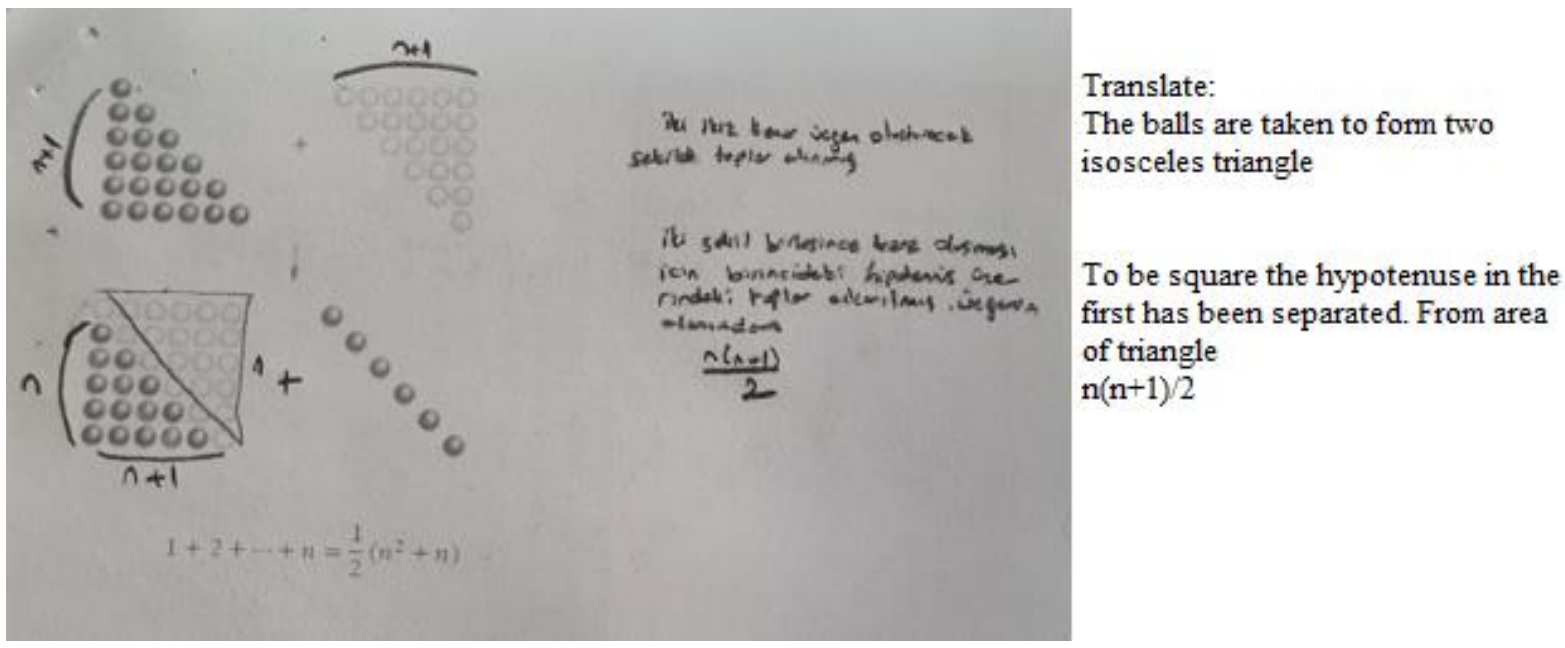

Figure 12. The answer to the subcategory for "Explaining visual for n"

The preservice mathematics teacher in Figure 13 interpreted the given image for $\mathrm{n}$ case and reached the formula and then applied the formula for $n=6$.

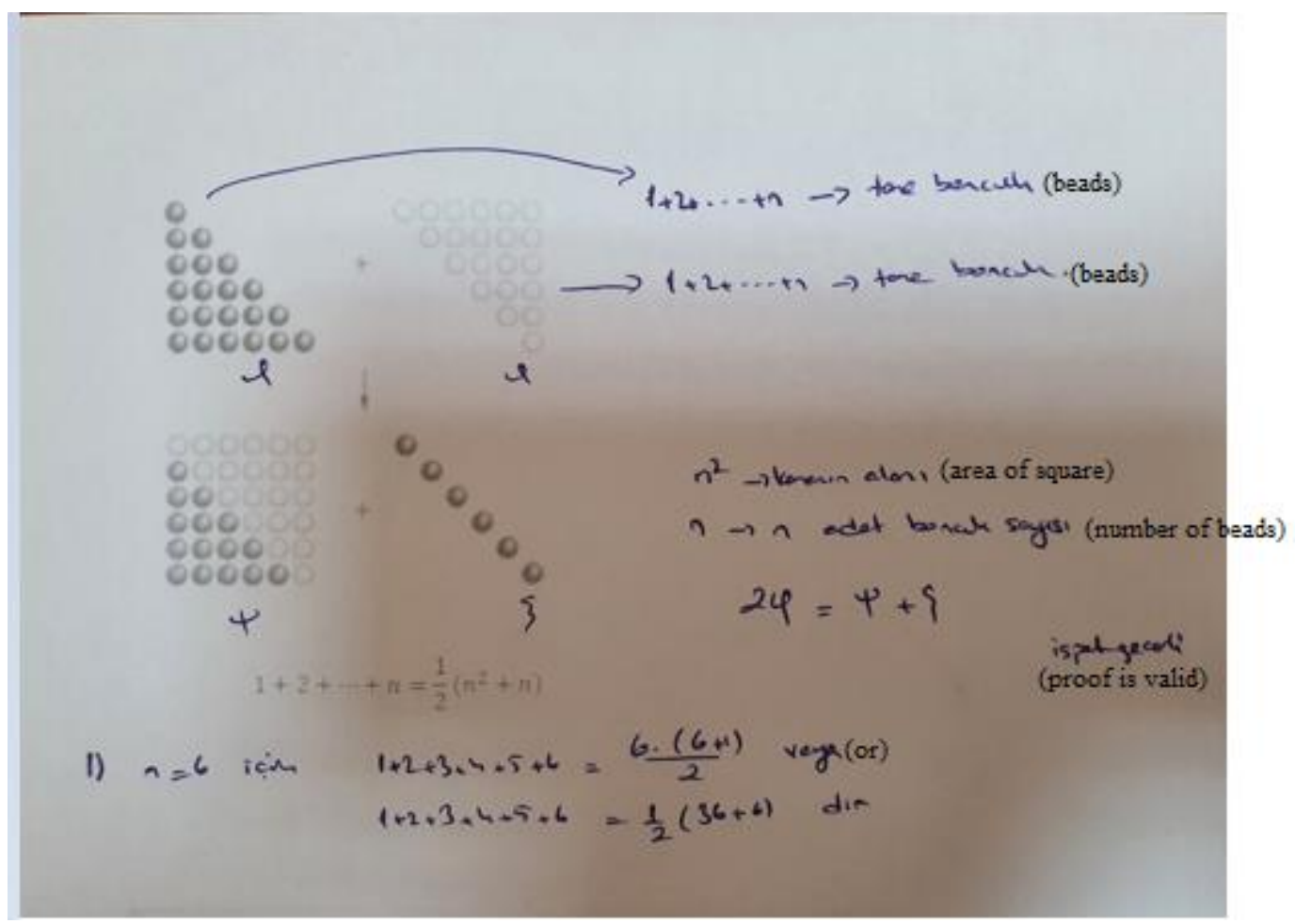

Figure 13. Answers to the subcategory for "explaining the visual for $\mathrm{n}$ and mentioning about the special case"

As can be seen from Figure 11 and Figure 12, preservice mathematics teachers have reached the formula by explaining the figure correctly. However, some preservice mathematics teachers explained the image given without mentioning the special case, while others interpreted the given visual for $\mathrm{n}$ case and applied the formula for the special case.

\section{Discussion and Conclusion}

Most of the preservice mathematics teachers were unable to explain the proof without words of the sum of integers from 1 to $\mathrm{n}$. Although there are many reasons for this, perhaps the most important is spatial thinking skills of preservice mathematics teachers. Because, as the PWW in this study, spatial processes such as rotation and reflection occur during the rearrangement of points or other visuals. This view is supported by Cain (2019). According to Cain (2019), proofs without words require spatial thinking. Also, according to Presmeg (1986) a visual image includes visual and spatial information. So, we can say that spatial thinking is needed to rearrange the points to obtain a square and arrive at the formula from its field. 
There are also pre-service mathematics teachers who tell the given image without any explanation. According to Gierdien (2007) definition, estimation, description, conclusion, observation, and generalization are the visualization process skills. Therefore, the fact that preservice mathematics teachers were able to explain the given visual without establishing a relationship shows that they may not have the skills of conclusion and generalizing. One of the points that draw attention here is a preservice mathematics teacher showed the accuracy of the equality from the area of triangle and the area of square for $n=6$. The preservice mathematics teacher was able to interpret the visual in proof without words and was able to use the necessary mathematical knowledge, but he/she was unable to generalize the given visual. Preservice mathematics teachers emphasized that the given form is an example or a special case and only exemplifies the sum of the numbers in the figure. They can explain the visual for the situation $n=6$. In fact, what is expected from preservice mathematics teachers is that they can make generalizations. Similar results have been observed in the studies of Polat (2018), Güler and Ekmekci (2016), Birinci (2010) and Arslan (2007). It is important to emphasizing abstraction and generalization when using visual methods. Because this aspect aided students in over-coming some of the difficulties associated with the one-case concreteness of an image or diagram (Presmeg, 1986). According to Kulpa (2008), the reason for this difficulty is that finding and detecting variables in visual proof. He said that more explicitly show the variable of the problem and a way to generalize the reasoning to arbitrary $\mathrm{n} \in \mathrm{N}$ by drawing a more elaborate diagram and using textual labels can clarify the reasoning even further and fix the correspondence between the diagrammatic proof and the formulation of the theorem. So, it can be said that explanatory texts and some visuals may be needed to generalize from the example. In the study of Dogan and William-Pierce (2021) they stated that teachers have important misconceptions about these proofs. Although we used the data collection tool which is more directional, the pre-service teachers could not generalize. They explained the special case for $n=6$. So, we can say pre-service teachers also have important misconceptions about these proofs. According to Gierdien (2007), a single case limitation in proof without words adversely affects the visualization process; according to Demircioğlu and Polat (2016), the inability to go to generalization is due to the lack of inductive thinking in students. Mason (1996) describes the ability to see in general the essence of algebraic thinking. Therefore, it can be thought that the difficulties of pre-service teachers in deciding what to generalize are caused by their difficulties in algebraic thinking. According to Flores (2000), one way to develop students' algebraic thinking is to use the geometric representations of numerical relations. Because visual proofs guide students to understand the steps of algebraic manipulation and give concrete meaning to algebraic terms. Also, one reason of this situation that preservice teachers cannot think with intuitive version of mathematical induction. Cain (2019) expresses generalization from the sample case as an intuitive version of mathematical induction. So, we can say that preservice teachers who can think with intuitive version of mathematical induction can see $\mathrm{n}$. step but others can see only for $n=6$.

Some of the preservice mathematics teachers explained the PWW with the Gauss method. While the accuracy of the formula related to the sum of consecutive integers can be indicated by the Gauss method, it is not considered correct since this is not the desired method. Also, the answers of some preservice mathematics teachers were not accepted because they had explained the image with another proof without words. Additionally, it was seen that some preservice mathematics teachers were able to reach the formula considering the first case in the given image. Thus, for the sum of the numbers from 1 to $n$, they formed a rectangle with side lengths $n$ and $(n+1)$, by combining the two isosceles triangles. They expressed that the asked formula was half of the area of the rectangle and that is, $\frac{n \cdot(n+1)}{2}$. This is a correct approach and is even given as an alternative proof (Nelsen, 1993; 2000; Lam, 2007; Larson, 1985; Giaquinto, 2007), but it is not an explanation of this image because they do not take into account the second case given in the visual. So, we can say that they had seen this proof without words before but they did not analyze the image correctly. Also, it can be said that preservice mathematics teachers, when they see the mathematical expression given with the proof without words, explain the proof that they are used to doing it without thinking about the visual, and thus they prove that they are focused on making proof and they are used to it. In particular, the presentation of proof by different and alternative means may indicate to students those mathematical expressions can be proved in multiple ways. This can prevent the mistake that the proofs are rigidly unchanged.

In future studies, the relationships between preservice mathematics teachers' spatial ability and proofs without words skills can be evaluated. There may be a new research problem that giving education on proof without words will influence the development of spatial ability and generalization skills. The same study can be done to determine the more comprehensive results achieved throughout Turkey. A parallel study can be done more deeply with primary and secondary mathematics teachers as well.

\section{Limitations}

The most important limitation of this study is that the data from the pre-service teachers were collected in written form. For this reason, the explanations could not be examined in detail based on the written data. The 
reasons for the statements made by the pre-service teachers could not be clarified. Also, one limitation of this study was that we examined the answers of a small set of preservice teachers in a university. The pre-service teachers engage with formal proof who are introduced formally to PWWs for the first time during the course. So maybe other pre-service teachers may engage with the same PWW differently. Further research is needed to determine these differences.

\section{References}

Almeida, D. (1996). Variation in proof standards: Implication for mathematics education. International Journal of Mathematical Education in Science and Technology, 27, 659-665.
https://doi.org/10.1080/0020739960270504

Alsina, C., \& Nelsen R. (2010). An invitation to proofs without words. European Journal of Pure and Applied Mathematics, $3(1)$, 118-127. http://www.labjor.unicamp.br/comciencia/files/matematica/ar_roger/ar_roger.pdf

Arslan, C. (2007). The development of elementary school students on their reasoning and proof ideas. (Publication No. 210145) [Doctoral dissertation, Uludag University]. Available from Council of Higher Education Thesis Center.

Altun, M. (2014). Liselerde matematik ögretimi. (5. ed). Aktüel Yayıncılık.

Balacheff, N. (1988). Aspects of proof in pupils' practice of school mathematics (D. En Pimm, Ed.). London: Hodder \& Stoughton.

Ball, D. L., Hoyles, C., Jahnke, H. N., \& Movshovitz-Hadar, N. (2002). The teaching of proof. In L. I. Tatsien (Ed.), Proceedings of the international congress of mathematicians, (pp. 907-920). Beijing. https://arxiv.org/pdf/math/0305021.pdf

Bardelle, C. (2010). Visual proofs: An experiment. In V. Durand-Guerrier et al (Eds.), CERME6, (251-260). Lyon. France. http://ife.ens-lyon.fr/publications/edition-electronique/cerme6/wg2-08- bardelle.pdf

Bell, C. J. (2011). Proof without words: A visual application of reasoning. Mathematics Teachers, 104(9), 690695. https://doi.org/10.5951/MT.104.9.0690

Birinci, K. S. (2010). Investigation of mathematics teacher candidates' proof processes in terms of processobject relationship (Publication No.279855) [Master's thesis, Marmara University]. Available from Council of Higher Education Thesis Center.

Britz, T., Mammoliti, A. \& Sørensen, H. K. (2014). Proof by picture: A selection of nice picture proofs. Parabola, 50(3), 1-8.

Brown, J. R. (1997). Proofs and pictures. British Journal for the Philosophy of Science, 48, 161-180. https://faculty.unlv.edu/jwood/unlv/Articles/Brown.pdf

Cain, A.J. (2019). Visual thinking and simplicity of proof. Philosophical Transactions A. 377, 1-13. https://doi.org/10.1098/rsta.2018.0032

Davis, P.J. (1993). Visual theorems. Educational Studies in Mathematics, 24(4), 333-344. https://doi.org/10.1007/BF01273369

Dove, I. (2002). Can pictures prove? Logique \& Analyze, 45(179), 309-340.

Demircioglu, H., \& Polat, K. (2015). Secondary mathematics pre-service teachers' opinions about proof without words. The Journal of Academic Social Science Studies, 41, 233-254. https://doi.org/10.9761/JASSS3171

Demircioglu, H., \& Polat, K. (2016). Secondary mathematics pre-service teachers' opinions about the difficulties with "proof without words". International Journal of Turkish Education Sciences, 4(7), 8299.

Dogan, M. F. (2019). The nature of middle school in-service teachers' engagements in proving-related activities. Cukurova University Faculty of Education Journal, 48(1), 100-130. https://doi.org/10.14812/cufej.442893

Dogan, M.F. (2020). Pre-service teachers' criteria for evaluating mathematical arguments that include generic examples. International Journal of Contemporary Educational Research, 7(1), 267-279. https://doi.org/10.33200/ij.jer.721136 
Dogan, M. F., \& Williams-Pierce, C. (2021). The role of generic examples in teachers' proving activities. Educational Studies in Mathematics,106, 133-150. https://doi.org/10.1007/s10649-020-10002-3

Doyle, T., Kutler, L., Miller, R., Schueller, A. (2014). Proof without words and beyond. Mathematical Association of America. https://doi:10.4169/convergence20140801

Duval R. (1999). Representation, vision and visualization: Cognitive functions in mathematical thinking. Basic issues for learning. In F. Hitt \& M. Santos (Eds.). Proceedings of the twenty-first annual meeting of the north American chapter of the international group for the psychology of mathematics education, 1, 326. https://files.eric.ed.gov/fulltext/ED466379.pdf

Flores, A. (2000). Geometric representations in the transition from arithmetic to algebra. In F. Hitt (Ed.). Representation and mathematics Visualization (pp. 9-29).

Giaquinto, M. (2007). Visual thinking in mathematics: An epistemological study. Oxford, UK: Oxford University Press. https://doi.org/10.1093/acprof:0so/9780199285945.001.0001

Gierdien, F. (2007). From "Proofs without words" to "Proofs that explain" in secondary mathematics. Pythagoras, 65, 53 - 62. https://doi.org/10.4102/pythagoras.v0i65.92

Güler, G., \& Ekmekci, S. (2016). Examination of the proof evaluation skills of the prospective mathematics teachers: The example of sum of successive odd numbers. Journal of Bayburt Education Faculty, $11(1), 60-81$.

Hanna, G. (1990). Some pedagogical aspects of proof. Interchange, 21(1), 6-13.

Hanna, G. (2000). Proof, Explanation and Exploration: An Overview. Educational Studies in Mathematics, 44, 5-23. https://doi.org/10.1023/A:1012737223465

Heinze, A., \& Reiss, K. (2004). The teaching of proof at lower secondary level-a video study. ZDM International Journal on Mathematics Education, 36(3), 98-104. https://doi.org/10.1007/BF02652777

Jamnik, M., Bundy, A., \& Green, I. (1997). Automation of diagrammatic reasoning. 15th international joint conference on artificial intelligence, 1, 528-533. San Mateo, CA. https://www.cl.cam.ac.uk/ mj201/publications/pub873.drii-ijcai1997.pdf

Kristiyajati, A. \& Wijaya, A. (2018). Teachers' perception on the use of "Proof without Words (PWWs)" visualization of arithmetic sequences. Journal of Physics: Conference Series, 1097, 1-7. https://doi.org/10.1088/1742-6596/1097/1/012144

Kulpa, Z. (2009). Main problems with diagrammatic reasoning. Part 1: The generalization problem. Foundations of Science, 14(1-2), 75-96. https://doi.org/10.1007/s10699-008-9148-5

Lam, T. T. (2007) Contextual approach in teaching mathematics: An example using the sum of series of positive integers, International Journal of Mathematical Education in Science and Technology, 38(2), 273-282, https://doi.org/10.1080/00207390600913376

Larson, L.C. (1985). A discrete look at $1+2+\ldots+n$. The College Mathematics Journal, 16, 369-382. https://doi.org/10.2307/2686996

Marrades, R., \& Gutierrez A. (2000). Proofs produced by secondary school students learning geometry in a dynamic computer environment. Educational Studies in Mathematics 44, 87-125. https://doi.org/10.1023/A:1012785106627

Mason, J. (1996). Expressing generality and roots of algebra. In N. Bernarz, C. Kieran, \& L. Lee (Eds.), Approaches to algebra: Perspectives for research and teaching (pp. 65-86). Dordrecht: Kluwer Academic Publishers. https://doi.org/10.1007/978-94-009-1732-3 5

Merriam, S. B. (2013). Nitel araştırma desen ve uygulama için bir rehber (Çev. Ed. Selahattin Turan). Nobel Yayıncılik.

Miller, $\quad$ R. $\quad$ L. (2012). $\quad$ On $\quad$ proofs $\quad$ without words. http://www.whitman.edu/mathematics/SeniorProjectArchive/2012/Miller.pdf

Nelsen. R. (1993). Proofs without words: Exercises in visual thinking. Mathematical Association of America.

Nelsen. R (2000). Proofs without words II: More exercises in visual thinking. Mathematical Association of America. 
Ugurel, I., Morali, H. S., Karahan, Ö., \& Boz, B. (2016). Mathematically gifted high school students' approaches to developing visual proofs (VP) and preliminary ideas about VP. International Journal of Education in Mathematics, Science and Technology, 4(3), 174-197. https://doi.org/10.18404/ijemst.61686

Polat, K. (2018). Proofs without words as an alternative proof method: Investigating of high school students' proof skills. (Publication No.503666) [Doctoral dissertation, Ataturk University]. Available from Council of Higher Education Thesis Center.

Polat, K. \& Akgün, L. (2020). Examining the processes of high school students to do proof without words. Education Reform Journal, 5(1), 8-26. https://doi.org/10.22596/erj2020.05.01.8.26

Presmeg, N., C. (1986). Visualization in high school mathematics. For the Learning of Mathematics, 6(3), 4246.

Rinvold, R. A., \& Lorange, A. (2011). Multimodal derivation and proof in algebra. In M. Pytlak, T. Rowland \& E. Swoboda (Eds.). Proceedings of CERME 7, 233-242, Poland. http://cerme8.metu.edu.tr/wgpapers/WG1/WG1_Rinvold.pdf

Rodd, M. M. (2000). On mathematical warrants: Proof does not always warrant, and a warrant may be other than a proof. Mathematical Thinking and Learning, 2(3), 221-244. https://doi.org $\underline{10.1207 / S 15327833 M T L 0203 \_4}$

Thornton, S. (2001). A picture is worth a thousand words. http://math.unipa.it/grim/AThornton251.PDF 